\title{
Epidemiological Study of Strongyloides stercoralis With a Comparative Diagnostic Approach, in Lorestan, West of Iran
}

\author{
Ebrahim Badparva ${ }^{1}$; Hassan Nayebzadeh ${ }^{2, *}$; Malek Hossein Barkhordari ${ }^{3}$; Behrooz \\ Ezzatpour $^{4}$
}

${ }^{1}$ Department of Parasitology and Mycology, Lorestan University of Medical Sciences, Khorramabad, IR Iran

${ }_{3}^{2}$ Department of Pathobiology, Faculty of Veterinary Medicine, Lorestan University, Khorramabad, IR Iran

${ }^{3}$ Department of Health Deputy, Lorestan University of Medical Sciences, Khorramabad, IR Iran

4 Medical Herbs Research Center, Lorestan University of Medical Sciences, Khorramabad, IR Iran

${ }^{*}$ Corresponding author: Hassan Nayebzadeh, Department of Pathobiology, Faculty of Veterinary Medicine, Lorestan University, Khorramabad, IR Iran. Tel.: +98-9166675416, Fax: +986612230999, E-mail: hassannayeb@yahoo.com

Received: December 11, 2013; Accepted: January 1, 2014

Background: Strongyloides stercoralis causes strongyloidiasis, one of the major parasitic infections in human worldwide.

Objectives: This study was carried out to examine the prevalence of S. stercoralis in the state of Lorestan, west of Iran, using a comparative diagnostic approach.

Materials and Methods: Stool specimens from a random population sample were examined with light microscope, using direct fecal smear, formalin-ether concentration, and nutrient agar plate culture.

Results: The prevalence of S. stercoralis in this study was $0.07 \%$. The statistical random sample in this study was 2839 people whose stool specimens were collected and examined using nutrient agar plate culture. The results showed only two infected persons. The same procedure was administered using direct fecal smear and formalin-ether concentration, which showed no result.

Conclusions: As a precautionary measure, a stool test based on nutrient agar plate culture is recommended for detection of S. stercoralis.

Keywords:Strongyloides stercoralis; Prevalence; Feces

\section{Background}

Strongyloidiasis is endemic in almost all parts of the world from Asia, to southeast Asia, to Africa and central and south America (1). In 1876, for the first time, Strongyloides stercoralis was observed in stool samples of on duty French soldiers in Vietnam. The soldiers had a severe form of diarrhea, more specifically known as cochin-china diarrhea (2). The infective larvae infects human by penetrating into the skin (1). S. stercoralis has a unique life cycle, capable of surviving in a human host for several years. It can cause autoinfection which may lead to chronic diseases (3). The complex life cycle of parthenogenetic female $S$. stercoralis enables it to reproduce without participation of a male (4). Most infections are asymptomatic; however, as these infections disseminate, hyper-infection may occur in immunecompromised and immune-deficient individuals, which may result in a fatal disease (3). There are several techniques for detecting larvae in stool samples, one of which is direct smear of feces in saline-lugol's iodine stain, formalin-ethyl acetate concentration, Harada-
Mori filter paper culture, Bearmann concentration, and nutrient agar plate culture (4).

\section{Objectives}

Strongyloidiasis is endemic in Iran with prevalence of $0.3 \%$ in general population, similar to several other countries (5). The aim of this study was to determine the epidemiological status of S. stercoralis by applying a comparative diagnostic approach in Lorestan Province, west of Iran.

\section{Materials and Methods}

A cross-sectional study was conducted in May 2011 and completed in March 2012 in the Lorestan Province, west of Iran. The population sample was chosen by randomized cluster sampling from the normal population, covered by all health centers affiliated with the Lorestan University of Medical Sciences. A questionnaire coupled with an interview were used to collect information about should ask for the results of a stool test based on nutrient agar plate culture.

Copyright @ 2014, Infectious Diseases and Tropical Medicine Research Center. This is an open-access article distributed under the terms of the Creative Commons Attribution License, which permits unrestricted use, distribution, and reproduction in any medium, provided the original work is properly cited. 
age, sex, education attainment, occupation, residency (urban/rural), and family health states of 2839 people, consisting of 1444 from rural and 1395 from urban areas. Stool specimens were collected from all family members aged two years or more. Prelabeled plastic containers for collection of stool specimens were given to all the participants. Each morning, the filled containers were collected. The stool samples were stored at ambient temperature and transferred to the laboratory. Specimens were examined with light microscope using direct fecal smear in normal saline-lugol's iodine stain and formalin-ether concentration techniques. Using nutrient agar plate culture, the stool specimens were incubated for at least two days. Data were analyzed using SPSS software (SPSS Inc., Chicago, USA).

\section{Results}

The infection percentage of $S$. stercoralis in this study was minute (0.07\%). From 2839 examined people, only two cases were observed: a 26-year-old man from a small touristic town in Lorestan, a summer-holiday destination for local and nonlocal tourists, and a nine-year-old boy from rural areas of Lorestan with inadequate health and hygiene facilities. The two cases did not demonstrate clinical symptoms.

\section{Discussion}

In the current study, using the nutrient agar plate culture method, S. stercoralis was detected in two cases. In contrast, examining the direct fecal smear as well as formalin-ether concentration yielded no result. The prevalence degrees of S. stercoralis vary in different parts of the world: in the province of Yunnan, China, it is 11.7\%; in Okinawa of Japan 9.6\%; in Chiang Mai of Thailand, $47.6 \%$; in Khammouane of Laos 23.8\%; in Maceio of Brazil $12 \%$ (6), and in Iran $0.03 \%$ (5). These differences appear to be attributed to factors such as climate, geographical conditions, socioeconomic characteristics, and the degree of improvements in hygiene and health. While the overall prevalence of S. stercoralis in Iran was $0.03 \%$, one of the studies conducted on mentally-retarded children in the southern and hot area of Bandar Abbas reported $17.31 \%$ (3). Similarly, another study on mentally-retarded children in Tehran reported it as 31.6\% (7). Mental retardation coupled with poor hygiene, enhance the risk of being affected by intestinal parasitic infections (3). Sayyari et al. (8) observed that there was no case of $S$. stercoralis in Iran. In this study, only formalin-ether concentration diagnosis method was used, which might explain the results. Agar plate culture is more accurate than direct smear. A research indicated that the accuracy of agar plate culture method was 4.4 times greater than direct smear (9). Despite being a time-consuming and long process, it is more sensitive and accurate for finding larvae in feces (10). In another study for determining the efficacy of stool examination for detection of Strongyloides infection, 1350 samples were collected from Japan, Brazil and Thailand and examined by four different methods: direct fecal smear, Harada-Mori filter paper, formalin-ether concentration, and agar plate culture. The agar plate culture method showed significantly better results compared to the others (11).

Researchers have mentioned that examination of duodenal aspirate is very sensitive and invasive; however, it is recommended to promptly show the presence of parasites in immunocompromised children with possible severe infection $(1,12)$. Helminthes are the conduits of soil-transmitted infections and a major health problem. Their most prevalent strains are Ascaris lumbricoides, Trichuris trichura, and the hook worms (13); while their most neglected one is S. stercoralis (3).

Generally, strongyloidiasis is considered a tropical disease; however, it is recommended that the Iranian physicians and healthcare providers pay more attention by asking the laboratories to provide them with stool test results, using the nutrient agar plate culture method and serological testing. Furthermore, it is recommended that physicians, in noticing gastrointestinal symptoms, or prior to chemotherapy or steroid therapy, ask for results of a stool test based on nutrient agar plate culture method.

\section{Acknowledgements}

The authors thank the Vice-Chancellor for Health and health centers affiliated to Lorestan University of Medical Sciences. We also thank Dr. M. H. Eftekhari for his kind assistance.

\section{Authors' Contributions}

Study concept, design and laboratory work: Ebrahim Badparva; analysis and interpretation of data and drafting of the manuscript: Hassan Nayebzadeh; collection of the specimens: Malek Hossein Barkhordari and Behrooz Ezzatpour.

\section{Financial Disclosure}

The authors declared no conflict of interests.

\section{Funding/Support}

This research was financially supported by the Vice Chancellor for Research, Lorestan University of Medical Sciences.

\section{References}

1. Lim S, Katz K, Krajden S, Fuksa M, Keystone JS, Kain KC. Complicated and fatal Strongyloides infection in Canadians: risk factors, diagnosis and management. CMAJ. 2004;171(5):479-84

2. Grove DI. Human Strongyloidiasis. Adv Parasitol.1996;38:251-309.

3. Shokri A, Sarasiabi KS, Teshnizi SH, Mahmoodi H. Prevalence of Strongyloides stercoralis and other intestinal parasitic infections among mentally retarded residents in central institution of southern Iran. Asian Pa J Trop Biomed. 2012;2(2):88-91.

4. Siddiqui AA, Berk SL. Diagnosis of Strongyloides stercoralis infection. Clin Infect Dis. 2001;33(7):1040-7. 
5. Rokni MB. The present status of human helminthic diseases in Iran. Ann Trop Med Parasitol. 2008;102(4):283-95.

6. Kobayashi JUN, Sato Y, Toma H, Shimabukuro I, Tasaki T, Takara $\mathrm{M}$, et al. Epidemiological features of strongyloides infection in Okinawa, Japan: Comparative study with other endemic areas. JPN J TROP Med H. 2000;28(1):9-14.

7. Yousefi H, Massoud J. [The problem of Strongyloides stercoralis infection in the Rofeideh mental retarded institute of Tehran]. SID. 2000;3(2):141-6.

8. Sayyari AA, Imanzadeh F, Bagheri Yazdi SA, Karami H, Yaghoobi M. Prevalence of intestinal parasitic infections in the Islamic Republic of Iran. East Mediterr Health J. 2005;11(3):377-83.

9. de Kaminsky RG. Evaluation of three methods for laboratory diagnosis of Strongyloides stercoralis infection. I Parasitol. 1993;79(2):277-80.

10. Zaha O, Hirata T, Kinjo F, Saito A. Strongyloidiasis--progress in diagnosis and treatment. Intern Med.2000;39(9):695-700.

11. Sato Y, Kobayashi J, Toma H, Shiroma Y. Efficacy of stool examination for detection of Strongyloides infection. Am J Trop Med Hyg. 1995;53(3):248-50.

12. Liu LX, Weller PF. Strongyloidiasis and other intestinal nematode infections. Infect Dis Clin North Am. 1993;7(3):655-82.

13. Alemu A, Atnafu A, Addis Z, Shiferaw Y, Teklu T, Mathewos B, et al. Soil transmitted helminths and schistosoma mansoni infections among school children in Zarima town, northwest Ethiopia. BMC Infect Dis. 2011;11:189. 